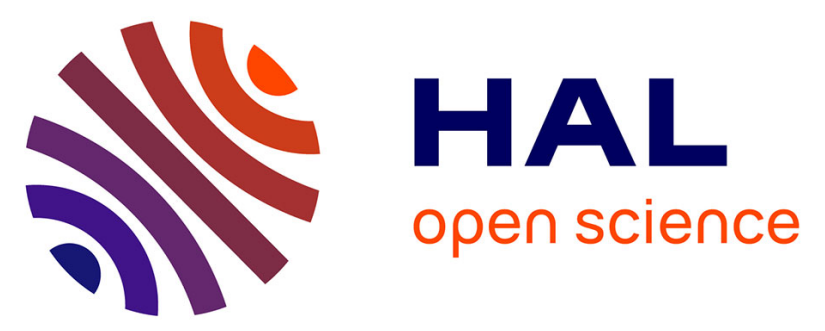

\title{
Halochromic Switch from the 1st to 2nd Near-Infrared Window of Diazapentalene-Dithienosilole Copolymers
}

Wissem Khelifi, Hussein Awada, Katarzyna Brymora, Sylvie Blanc, Lionel Hirsch, Frédéric Castet, Antoine Bousquet, Christine Lartigau-Dagron

\section{- To cite this version:}

Wissem Khelifi, Hussein Awada, Katarzyna Brymora, Sylvie Blanc, Lionel Hirsch, et al.. Halochromic Switch from the 1st to 2nd Near-Infrared Window of Diazapentalene-Dithienosilole Copolymers. Macromolecules, 2019, 52 (13), pp.4820-4827. 10.1021/acs.macromol.9b00675 . hal-02178217

\section{HAL Id: hal-02178217 \\ https://hal-univ-pau.archives-ouvertes.fr/hal-02178217}

Submitted on 12 Nov 2020

HAL is a multi-disciplinary open access archive for the deposit and dissemination of scientific research documents, whether they are published or not. The documents may come from teaching and research institutions in France or abroad, or from public or private research centers.
L'archive ouverte pluridisciplinaire HAL, est destinée au dépôt et à la diffusion de documents scientifiques de niveau recherche, publiés ou non, émanant des établissements d'enseignement et de recherche français ou étrangers, des laboratoires publics ou privés. 


\section{Halochromic switch from the $1^{\text {st }}$ to $2^{\text {nd }}$ Near Infrared window of Diazapentalene-}

\section{Dithienosilole copolymers}

Wissem Khelifi ${ }^{\mathrm{a}}$, Hussein Awada ${ }^{\mathrm{a}}$, Katarzyna Brymora ${ }^{\mathrm{b}}$, Sylvie Blanc ${ }^{\mathrm{a}}$, Lionel Hirsch ${ }^{\mathrm{c}}$, Frédéric Castet ${ }^{\mathrm{b}}$, Antoine Bousquet* ${ }^{\mathrm{a}}$, Christine Lartigau-Dagron*a

${ }^{a}$ CNRS/ Univ Pau \& Pays Adour/ E2S UPPA, Institut des Sciences Analytiques et de Physicochimie pour l'Environnement et les Matériaux, UMR 5254, 64000, PAU, FRANCE

${ }^{b}$ Institut des Sciences Moléculaires (ISM, UMR CNRS 5255), Université de Bordeaux, 351 cours de la Libération, 33405 Talence, France

${ }^{c}$ Laboratoire de l'Intégration du Matériau au Système (IMS, UMR CNRS 5218), Université de Bordeaux, ENSCBP, 16 Avenue Pey-Berland, 33607 Pessac Cedex, France

Corresponding authors: antoine.bousquet@univ-pau.fr or christine.lartigau-dagron@univ-pau.fr

"for Table of Contents use only"

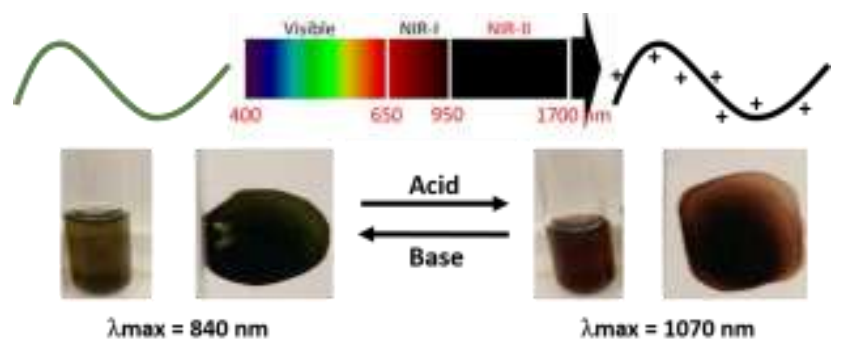

\section{Abstract : (100-150 words)}

Halochromic switch from the 1st to 2nd Near Infrared window of Diazapentalene-Dithienosilole copolymers is reported. The diazapentalene repeat unit presents an imine group that can be either protonated by a Bronsted acid or coordinated with a Lewis acid. As a consequence, the wavelength of maximum absorbance was 
switched from $840 \mathrm{~nm}$ to $1070 \mathrm{~nm}$. Experimental data obtained by spectrophotometry and cyclic voltammetry were combined with theoretical DFT calculations to explain the reversible halochromic behavior of these copolymers and the adducts that are formed during the reactions. Since they can undergo analyte-induced absorption shifts in the near infrared, these materials should prove useful as biological/chemical sensors.

\section{Introduction}

Owing to their ability to conduct electrons, to absorb or emit light, conjugated polymers (CPs) constitute a class of materials with high potential in a broad range of applications in organic electronics, from photovoltaics to sensors. ${ }^{1-3}$ Organic-based devices promise low costs and interesting properties based on their low density, conformability, flexibility and versatility with a wide range of chemical structures. Initial works were dedicated to the development of new CPs with improved processabilities, a particular target being the design of soluble materials. For this purpose, side alkyl chains were added to repeat units, making CPs soluble in common organic solvents but also in water after introduction of polar groups. ${ }^{4}$ A chromism behavior, which denotes the reversible variation of the electronic absorption properties of a material, can be observed in CPs under the influence of temperature (thermochromism) or $\mathrm{pH}$ variation (halochromism). ${ }^{5}$ Chromism in CPs is attributed to intramolecular conformational changes, such as a twist in the planarity of the main chain inducing a reduction of the conjugation length. ${ }^{6}$ It can also be induced by creation/destruction of intermolecular interactions such as $\pi-\pi$ stacking between the aromatic repeat units. ${ }^{7}$ Destruction of these interactions can be provoked in film by elevation of the temperature above the melting point of the polymer, ${ }^{8}$ or in solution by using a good solvent for the polymer chains. ${ }^{9}$

Conjugated polymers including basic nitrogen atoms in the aromatic ring (imine groups) offer the possibility of lone pair protonation, as a way of modifying their electronic and optical properties. Such halochromic materials, that change color in the presence of protons, may be used as $\mathrm{pH}$ indicators or proton probes. ${ }^{10}$ As typical examples, pyridine polymers have been submitted to protonation via addition of mineral and organic Brønsted acids. ${ }^{11}$ Upon protonation, the color of the solution changes with a bathochromic shift of the maximal absorption wavelength, attributed to an increase of the system planarity due to intramolecular hydrogen bonds between alkoxy side chains and the hydrogen associated to the pyridine protonation. Basic nitrogen atoms in 
the aromatic ring are also able to bind Lewis acids. This interaction influences the degree of charge-transfer character of conjugated (macro)molecules. ${ }^{12-15}$ Compared to protonation, Lewis acid addition allows the modulation of optical properties via the acid strength, and avoids the presence of free mobile counter ions in the matrix. ${ }^{16} \mathrm{~N}$ 'Guyen and coworkers demonstrated the possibility of using Lewis acid-base interaction to tune the electroluminescence of a conjugated polymer containing a pyridine repetitive unit. As a result, the modified polymer exhibited longer excited state lifetimes and larger quantum yields than the native material, as well as a maximum emission wavelength red-shifted by $80 \mathrm{~nm} .{ }^{17}$ The same behavior was also demonstrated on a fluorene-based conjugated polymer, and was used to design tunable organic light emitting devices (OLED). ${ }^{18}$ Density functional theory (DFT) calculations performed on such systems showed that protonation or Lewis acid binding resulted in decreasing the electron density of the acceptor unit. This interaction reduces the (macro)molecules band-gap, namely the gap between the lowest unoccupied molecular orbital (LUMO) and the highest occupied molecular orbital (HOMO) energy levels, with a strong decrease of the LUMO energy. ${ }^{12,16}$

Up to now, halochromism has mostly been demonstrated on chromophores absorbing in the UV-visible range. However, research in the field of Infra-Red (IR) technologies is in strong development, driven by technological needs in military and civilian applications, such as imaging, optical communications, energy or sensing. ${ }^{19}$ Indeed, since $50 \%$ of the solar energy falls into the IR spectral region, photovoltaic materials are under development to increase solar cells efficiency. ${ }^{20-21}$ IR-materials are also synthesized for biosensing and bioimaging because IR light penetrates into tissues, the so-called "biological window". ${ }^{22}$ To design organic IR materials, the basic principle is to reduce the bandgap. Specifically, synthesis of electron donor-acceptor (D-A) alternating conjugated copolymers, have demonstrated high potential to decrease the bandgap under $1.5 \mathrm{eV}$, leading to IR-absorbing or emitting materials. ${ }^{2,23}$ For the moment, most of these organic materials showed a maximum absorption peaks falling in the first NIR optical window covering $750-1000 \mathrm{~nm}$. Actually, the second NIR optical window covering $1000-1350 \mathrm{~nm}$ is more promising for biological applications due to its higher photothermal conversion and deeper tissue penetration. ${ }^{24}$

In the present study we report the synthesis of a new low bandgap copolymer based on the 2,5-diazapentalene (DAP) unit, derived from the diketopyrrolopyrrole (DPP) chromophore. We combine the strong acceptor DAP unit with the dithienosilole (DTS), a photostable ${ }^{25}$ electron donor, that allows the introduction of solubilizing alkyl chains onto the silicon atom. As the result of the polymerization, an IR-material was synthesized with a 
maximum absorption at $850 \mathrm{~nm}$. Upon protonation of the DAP unit with Brønsted acids or its complexation with Lewis acids, the maximum of absorption is further shifted up to $1100 \mathrm{~nm}$ in the second NIR optical window. Using a combination of spectrometry, cyclic voltammetry and DFT calculations, we identify the Brønsted and Lewis adducts that are formed, and show the potential of this material for a variety of optoelectronics applications.

\section{Experimental and computational section}

\subsection{Experimental}

\section{Synthesis of 3,6-Dithiophene-2-yl-2,5-dihydropyrrolo[3,4-c]pyrrole-1,4-dione (DPP) (Scheme 1i)}

In a $250 \mathrm{ml}$ double necked round bottom flask with a magnetic stirring bar, sodium ( $3.5 \mathrm{~g}, 0.15 \mathrm{~mol})$ was added to $60 \mathrm{ml}$ of t-amyl alcohol with a small amount of iron(III) chloride anhydrous (48 $\mathrm{mg}, 0.3 \mathrm{mmol}$ ). The mixture was stirred under inert atmosphere $\left(\mathrm{N}_{2}\right)$ for $1 \mathrm{~h}$ at $110{ }^{\circ} \mathrm{C}$, until complete sodium dissolution. The mixture was then cooled to $80{ }^{\circ} \mathrm{C}$ and 2-thiophene-carbonitryle $(9.5 \mathrm{~g}, 0.087 \mathrm{~mol})$ was added in one shot; then a solution of di-isopropylsuccinate $(7.092 \mathrm{~g}, 0.035 \mathrm{~mol})$ in t-amyl alcohol was added drop-wise using a $100 \mathrm{ml}$ dropping funnel. After addition completion, the reaction was left at $85{ }^{\circ} \mathrm{C}$ for $5 \mathrm{~h}$. The brown-red mixture was cooled at room temperature and filtered on a Büchner funnel. The brown-red solid filtrate was washed several times with warm deionized water and methanol. The final product was dried under vacuum until complete solvent removal. $\left(9 \mathrm{~g}\right.$, yield= 85\%) ${ }^{1} \mathrm{H}$ NMR (400 MHz, $\left.\mathrm{d}_{6}-\mathrm{DMSO}\right) \delta(\mathrm{ppm}): 11.24(\mathrm{~s}, 2 \mathrm{H}), 8.21(\mathrm{~d}, 2 \mathrm{H}), 7.96(\mathrm{~d}, 2 \mathrm{H})$, $7.31(\mathrm{dd}, 2 \mathrm{H})$

\section{Synthesis of 1,4-Bis(Ethylhexylthio)-3,6-di(thiophen-2-yl)pyrrolo[3,4-c]pyrrole (DPP-EH) (Scheme 1ii)}

A two necked $100 \mathrm{~mL}$ round bottom flask with a magnetic stirring bar, was charged with $(2.0 \mathrm{~g}, 0.007 \mathrm{~mol})$ of 3,6-bis (thiophen-2-yl)-2H, 5H-pyrrolo [3,4-c]pyrrole-1,4-dione (DPP) in anhydrous DMF and stirred under inert atmosphere $\left(\mathrm{N}_{2}\right)$ for $1 \mathrm{~h}$. $(3.22 \mathrm{~g}, 0.023 \mathrm{~mol})$ of anhydrous potassium carbonate $\left(\mathrm{K}_{2} \mathrm{CO}_{3}\right)$ was added, together with $(3.55 \mathrm{~mL}, 0.02 \mathrm{~mol})$ of $\mathrm{C}_{8} \mathrm{H}_{17}-\mathrm{Br}$ and $(0.018 \mathrm{~g}, 0.06 \mathrm{mmoL})$ of 18-crown-6. The mixture was stirred over night at $120^{\circ} \mathrm{C}$. The mixture was filtered on a Büchner funnel and the filtrate washed several times with warm deionized water and methanol. Then the crude product was purified by column chromatography using hexane: dichloromethane (1:1) as the eluent. The product was dried under vacuum to give a dark red 
solid. $(2.19 \mathrm{~g}$, yield $=80 \%){ }^{1} \mathrm{H}$ NMR $\left(400 \mathrm{MHz} \mathrm{CDCl}_{3}\right) \delta(\mathrm{ppm})=8.12(\mathrm{~d}, 2 \mathrm{H}), 7.64(\mathrm{~d}, 2 \mathrm{H}), 7.33-7.24(\mathrm{~m}$, 2H), 3.65-3.45 (m, 4H), 1.96-1.74 (m, 2H), 1.66-1.25 (m, 16H), 1.11-0.81 (m, 12H).

\section{Synthesis of 1,4-Bis(5-bromothiophen-2-yl)-3,6-bis(Ethylhexylthio)pyrrolo[3,4-c]pyrrole (DPP-EH-Br $)$} (Scheme 1iii)

A one neck $100 \mathrm{ml}$ round bottom flask with magnetic stirring bar was charged with $(2.0 \mathrm{~g}, 0.005 \mathrm{~mol})$ of DPPEH in $50 \mathrm{~mL}$ of chloroform. After $30 \mathrm{~min}$ of stirring at room temperature, NBS $(1.91 \mathrm{~g}, 0.011 \mathrm{~mol})$ was added in small portions. The mixture was stirred at $60^{\circ} \mathrm{C}$ for $3 \mathrm{~h}$ in the dark. Then chloroform was evaporated, and the resulting dark red solid was purified by chromatography column using hexane:dichloromethane $(2: 1)$ as the eluent to give the product as a red solid. $(2,21 \mathrm{~g}$, yield $=80 \%){ }^{1} \mathrm{H} \mathrm{NMR}\left(400 \mathrm{MHz}, \mathrm{CDCl}_{3}\right) \delta(\mathrm{ppm})=8.66(\mathrm{~d}$, 2H), $7.23(\mathrm{~d}, 2 \mathrm{H}), 4.04-3.85(\mathrm{~m}, 4 \mathrm{H}), 1.84(\mathrm{~s}, 2 \mathrm{H}), 1.41-1.19(\mathrm{~m}, 16 \mathrm{H}), 0.88(\mathrm{~m}, 12 \mathrm{H}) .{ }^{13} \mathrm{C} \mathrm{NMR}\left(\mathrm{CDCl}_{3}\right.$, $75 \mathrm{MHz}) \delta(\mathrm{ppm})=161.13,139.39,135.40,131.46,131.41,119.03,113.60,45.99,39.08,30.15,28.30,23.55$, $23.03,14.02,10.46$

Synthesis of 3,6-Di(thiophen-2-yl)-2,5-dihydropyrrolo[3,4-c]pyrrole-1,4-dithione (2) (Scheme 1v, adapted from ${ }^{14}$ )

A flamed-dried $200 \mathrm{ml}$ round flask bottom was flushed by $\mathrm{N}_{2}$ and charged with DPP (1 g, $\left.3.33 \mathrm{mmol}\right)$ and anhydrous chlorobenzene $(50 \mathrm{ml})$. After complete solubilisation, Lawesson's reagent $(2.7 \mathrm{~g}, 6.67 \mathrm{mmol})$ was added and the reaction was flushed by $\mathrm{N}_{2}$ and was allowed to react for $8 \mathrm{~h}$ at $135^{\circ} \mathrm{C}$. When the color of the solution turns dark green indicating the formation of the desired thiolactam intermediate, the solution mixture is precipitated in $500 \mathrm{~mL}$ methanol. Then it was filtered through Soxhlet thimble and washed by ethanol to remove any phosphate by-products that could lead to the degradation of the product The desired dark green solid was dried under vacuum for $24 \mathrm{~h}$ and stored under nitrogen and in the dark. A red solid powder was obtained (0.9 g, Yield $80 \%) .{ }^{1} \mathrm{H}$ NMR (400 MHz, DMSO-d6) $\delta(\mathrm{ppm}): 12.82(\mathrm{~s}, 2 \mathrm{H}), 9.00(\mathrm{dd}, 2 \mathrm{H}), 8.06(\mathrm{dd}$, 2H), $7.39(\mathrm{dd}, 2 \mathrm{H})$.

\section{1,4-Bis(Ethylhexylthio)-3,6-di(thiophen-2-yl)pyrrolo[3,4-c]pyrrole (3) (Scheme 1vi)}

In a flamed-dried $100 \mathrm{ml}$ round bottom flask bottom, DTPP (2 g, $6.02 \mathrm{mmol})$, ethylhexylbromide $(2.31 \mathrm{ml}, 13$ $\mathrm{mmol})$, anhydrous powdered $\mathrm{K}_{2} \mathrm{CO}_{3}(2.8 \mathrm{~g}, 20 \mathrm{mmol})$ were dissolved in dry acetone $(100 \mathrm{~mL})$. The reaction was bubbled with nitrogen for $15 \mathrm{~min}$ and stirred at $80^{\circ} \mathrm{C}$ overnight. The reaction solvent was removed by 
vacuum and the crude compound was extracted with chloroform and dried over $\mathrm{MgSO}_{4}$. After concentrating the product under vacuum, it was purified by silica gel chromatography column using Hexane: DCM (60:40) (v:v) as eluent and then dried for $24 \mathrm{~h}$ under vacuum. The product was recovered as a dark solid (1.67 $\mathrm{g}$, yield= 50 \%). ${ }^{1} \mathrm{H}$ NMR (400 MHz, $\left.\mathrm{CDCl}_{3}\right) \delta(\mathrm{ppm}): 8.12(\mathrm{~d}, 2 \mathrm{H}), 7.64(\mathrm{~d}, 2 \mathrm{H}), 7.33-7.24(\mathrm{~m}, 2 \mathrm{H}), 3.65-3.45(\mathrm{~m}, 4 \mathrm{H})$, $1.96-1.74(\mathrm{~m}, 2 \mathrm{H}), 1.66-1.25(\mathrm{~m}, 16 \mathrm{H}), 1.11-0.81(\mathrm{~m}, 12 \mathrm{H})$.

\section{1,4-Bis(5-bromothiophen-2-yl)-3,6-bis(Ethylhexylthio)pyrrolo[3,4-c]pyrrole (4) (Scheme 1vii)}

N-bromosuccinimide $(0.71 \mathrm{~g}, 4 \mathrm{mmol})$ was slowly added to a solution of 1,4-Bis(Ethylhexylthio)-3,6di(thiophen-2-yl)pyrrolo[3,4-c]pyrrole $(1 \mathrm{~g}, 1.8 \mathrm{mmol})$ in dry $\mathrm{CHCl}_{3}(50 \mathrm{ml})$. The mixture was stirred, at room temperature, in the dark for 4 hours. The reaction was followed by thin layer chromatography (TLC). The reaction was quenched with water $(10 \mathrm{ml})$, and the aqueous phase was extracted with $\mathrm{CH}_{2} \mathrm{Cl}_{2}$. The organic phases were combined, and washed with water, then dried over $\mathrm{MgSO}_{4}$. The crude product was absorbed onto silica gel, and purified using silica flash chromatography, with the eluent Hexane: $\mathrm{CH}_{2} \mathrm{Cl}_{2}(50: 50)$ (v:v). The product was then washed with methanol and dried under strong vacuum overnight, giving dark solid (0.96 mg, Yield=75\%). ${ }^{1} \mathrm{H}$ NMR (400 MHz, CDCl3) $\delta$ (ppm): 7.78 (d, 2H), $7.22(\mathrm{~d}, 2 \mathrm{H}), 3.52-3.45$ (m, 4H), 1.78-1.76 $(\mathrm{m}, 2 \mathrm{H}), 1.51-0.87(\mathrm{~m}, 28 \mathrm{H})$.

\section{Synthesis of $\left[\left(4,4^{\prime}-\right.\right.$ bis(2-ethylhexyl)dithieno[3,2-b:2',3'-d]silole)-2,6-diyl-alt-1,4-Bis(5-bromothiophen-2-} yl)-3,6-bis(Ethylhexylthio)pyrrolo[3,4-c]pyrrole-1,4-dione] (DAP-DTS) or (DPP-DTS) copolymers. (Scheme 1iv)

In a $10 \mathrm{~mL}$ high pressure tube equipped with a sealed septum were added the brominated monomer (275 $\mathrm{mg}$, 0.4mmol), with 4,4'-Bis (2-ethyl-hexyl)-5,5'-bis(trimethyltin)-dithieno[3,2-b:2',3'-d]silole (DTSSn) (300 mg, 0.4mmol), tris(dibenzylideneacetone) dipalladium(0) (7.38 mg, $0.02 \mathrm{eq})$, tri(o-tolyl)phosphine (12.27 mg, 0.1eq) and dissolved in $3 \mathrm{ml}$ of anhydrous chlorobenzene solution in the glovebox. The tube was subjected to heating at $130{ }^{\circ} \mathrm{C}$ for $24 \mathrm{~h}$. After cooling to room temperature, the resulting viscous liquid was dissolved in chlorobenzene then precipitated into acetone. The solid was filtered through a Soxhlet thimble and then subjected to Soxhlet successive extractions with methanol, acetone, cyclohexane, chlorobenzene. The chlorobenzene fraction was concentrated and precipitated into methanol, and the precipitant was filtered and 
dried under high vacuum to either P(DAP-DTS) $(312 \mathrm{mg}$, Yield $=80 \%)$ or P(DPP-DTS) $(301 \mathrm{mg}$, Yield $=80$ $\%)$ as a dark-black solid.

\section{Characterization}

Nuclear Magnetic Resonance (NMR) spectroscopy. Proton, carbon and heteronuclear multiple-bond correlation (HMBC) spectra were recorded in deuterated chloroform as a solvent using a Brüker $400 \mathrm{MHz}$ spectrometer at $25^{\circ} \mathrm{C}$.

Size Exclusion Chromatographie (SEC) was performed using a bank of 4 columns (Shodex KF801, 802.5, 804 and 806) each $300 \mathrm{~mm} \times 8 \mathrm{~mm}$ at $30{ }^{\circ} \mathrm{C}$ with THF eluent at a flow rate of $1.0 \mathrm{ml} . \mathrm{min}-1$ controlled by a Malvern pump (Viskotek, VE1122) and connected to Malvern VE3580 refractive index (RI) and Malvern VE3210 UV-visible detectors. Conventional calibration was performed against polystyrene standards.

Absorption Spectroscopy. The absorption spectra were recorded at room temperature with a double beam Cary 5000 spectrophotometer in steps of $1 \mathrm{~nm}$ in the range 400-1600 nm using a $1 \mathrm{~cm}$ quartz optical cell (Hellma).

Electrochemistry. The solution were prepared as follow: In a $25 \mathrm{ml}$ graduated volumetric flask, a mother solution of $\mathrm{P}(\mathrm{DAP}-\mathrm{DTS})\left(5.10^{-3} \mathrm{~g} / \mathrm{L}, \mathrm{C}=5.2 \times 10^{-6} \mathrm{~mol} / \mathrm{L}\right)$ was prepared. A constant volume of polymer solution ( $3 \mathrm{~mL}$ ) was placed in a quartz cuvette before starting the addition of acid. For the titration with $\mathrm{HCL}, \mathrm{BF}_{3}$ and TFA, the titrants were dispersed as a neat liquid using a micropipette. However, for $\mathrm{AlCl}_{3}$ and $\mathrm{FeCl}_{3}$ chloroform solutions $\left(\mathrm{C}=10^{-2} \mathrm{~mol} / \mathrm{L}\right)$ were prepared. The withdrawn volumes were calculated based on the molar equivalent of each acid with respect to the repeat unit and gradually increased to reach a full protonation of the polymer chains. After adding each aliquot of titrant, the sample was gently shaken for 2 min and placed in the sample chamber.

Cyclic Voltammetry (CV). A standard three-electrode electrochemical setup (AUTOLAB PGSTAT 101) consisting of a glassy carbon or a platinium disk as working electrode ( $2 \mathrm{~mm}$ diameter), a platinum foil as counter electrode, and a $\mathrm{Ag} / \mathrm{AgCl}$ as reference electrode, was used in the electrochemical experiments. At the end of each experiment performed in $\mathrm{CH}_{3} \mathrm{CN} / \mathrm{Bu}_{4} \mathrm{NPF}_{6}(0.1 \mathrm{M})$, the standard potential of the ferrocenium/ferrocene couple, $\mathrm{E}_{\mathrm{Fe}}$, was measured, and all potentials were referenced against SCE using a previous determination of $\mathrm{E}_{\mathrm{Fe}}=0.41 \mathrm{~V}$ versus $\mathrm{SCE}$ in $\mathrm{CH}_{3} \mathrm{CN}$.(ref 1) Polymers were drop casted from a 10 
$\mathrm{mg} / \mathrm{mL}$ polymer solution in chlorobenzene/ $\mathrm{Bu}_{4} \mathrm{NPF}_{6}(0,1 \mathrm{M})$ on the working electrode. $\mathrm{CV}$ gives direct information of the oxidation and reduction potentials of materials. The oxidation process corresponds to removal of the electron from the HOMO energy level, while the reduction corresponds to electron addition to the LUMO energy level of the material. Therefore HOMO and LUMO energy levels can be estimated using the empirical equations: $\mathrm{E}_{\mathrm{HOMO}}=-\left(\mathrm{E}_{\mathrm{ox}}+4.7\right)$ and $\mathrm{E}_{\mathrm{LUMO}}=-\left(\mathrm{E}_{\mathrm{red}}+4.7\right)$, where $\mathrm{E}_{\mathrm{ox}}$ and $\mathrm{E}_{\mathrm{red}}$ are respectively the onset potentials for oxidation and reduction peaks relative to SCE and 4.7 the factor connecting SCE to vacuum ${ }^{26}$. The onset potentials are determined by the tangent method (see supporting information). Only values from the first sweep on a film were used as the film is changed or destroyed during the first oxidation. The scan rate used was $0.1 \mathrm{~V} \cdot \mathrm{s}^{-1}$.

\subsection{Quantum chemical calculations}

Electronic and optical properties of DAP-DTS copolymers were evaluated by using the standard oligomer approach, in which the properties of oligomers containing an increasing number of repeat units are first calculated, and then extrapolated to infinite polymeric chains. ${ }^{27-31}$ In line with former studies, ${ }^{32}$ geometry optimizations of increasingly large oligomers (from $n=1$ to $n=5$ repeating units) were undertaken in the gas phase using density functional theory (DFT) with the M06-2X $\mathrm{X}^{33}$ exchange-correlation functional (XCF) and the 6-311G(d) basis set. This XCF incorporates a large amount (54\%) of exact Hartree-Fock (HF) exchange, which is necessary to reliably describe the geometrical features of extended $\pi$-conjugated systems, namely torsion angles and bond length alternation (BLA). ${ }^{34-35}$ The B3LYP XCF, which contains only $25 \%$ of HF exchange and is thus inadequate for predicting changes in properties as a function of system size, ${ }^{29}$ was nevertheless used to evaluate the electronic properties of monomeric units, since it provides good correlations between experimental redox potentials and theoretical HOMO/LUMO energies of small conjugated molecules. ${ }^{36}$ All geometry optimizations up to $n=3$ monomeric units were followed by vibrational calculations to ascertain that optimized geometries correspond to true minima on the potential energy surface. In all calculations, solubilizing alkyl chains appended to the DTS units were replaced by simple methyl groups.

Vertical excitation energies and oscillator strengths of increasing-size oligomers were determined using timedependent (TD) DFT at the M06-2X/6-311G(d) level. Solvent effects (chloroform) were taken into account by using the Integral Equation Formalism of the Polarizable Continuum Model (IEF-PCM). ${ }^{37} \mathrm{~S}_{0} \rightarrow \mathrm{S}_{1}$ transition 
energies in the polymer limit $\left(\Delta \mathrm{E}_{01}^{\infty}\right)$ were evaluated using the 2-parameter fitting equation issued from the Kuhn's coupled oscillator model: ${ }^{38}$

$$
\mathrm{E}(\mathrm{N})=E_{1} \sqrt{1+\mathrm{D}_{k} \cos \left(\frac{\pi}{N+1}\right)}
$$

where $N$ is the number of double bonds along the shortest conjugation pathway connecting the terminal atoms of the oligomer backbone. The fitting parameters, $E_{1}$ and $D_{k}$, describe respectively the transition energy of a formal double bond, and the relative force constant measuring how strongly the double bonds are coupled through single bonds. Therefore, $E_{1}$ is intrinsically related to the optical gap of the repeating units, while $D_{k}$ depends on the planarity of the molecular backbone and on the BLA along the $\pi$-conjugated skeleton. The limit case $\mathrm{D}_{k}=-1$ corresponds to a situation in which all bonds are identical $(\mathrm{BLA}=0)$ and gives rise to an optical gap equal to zero in the polymer limit. All calculations were performed with the Gaussian09 package. ${ }^{39}$

\section{Results and Discussion}

\subsection{Synthesis of the DAP-DTS polymer}

The synthetic routes of the diketopyrrolopyrrole (DPP) and diazapentalene (DAP) monomers, as well as of the $\mathrm{P}(\mathrm{DPP}-\mathrm{DTS})$ and P(DAP-DTS) copolymers are described in Scheme 1. The synthetic procedure was adapted from Wang and coworkers, who showed that the substitution of the DPP by a DAP unit in donor-acceptor copolymers leads to a shift of the maximum absorption of around $100 \mathrm{~nm} .{ }^{14,40}$ Moreover, the DAP unit presents basic nitrogen atoms in the aromatic ring that can be protonated by a Brønsted acid. ${ }^{15}$ We explored two synthetic strategies for the elaboration of the alternated copolymer poly(diazapentalene-alt-dithienosilole). The first route started with the synthesis of diketopyrrolopyrrole (DPP) in two steps, illustrated in Scheme 1 (steps i and ii). Then, the dibromo-DPP was prepared for a subsequent polymerization via Stille polycoupling (steps iii and iv) with a commercial di-stanilated dithienosilole (DTS). The last step of this first strategy consists in the chemical modification of the resulting poly(DPP-DTS) with the Lawesson's reagent to transform the lactam in thiolactam. During this step we observed precipitation of the copolymer in chlorobenzene reflux, and we were unable to solubilize it even with different solvent Soxhlet extractions. This behavior was attributed to a loss of the side alkyl chains during the last step. 


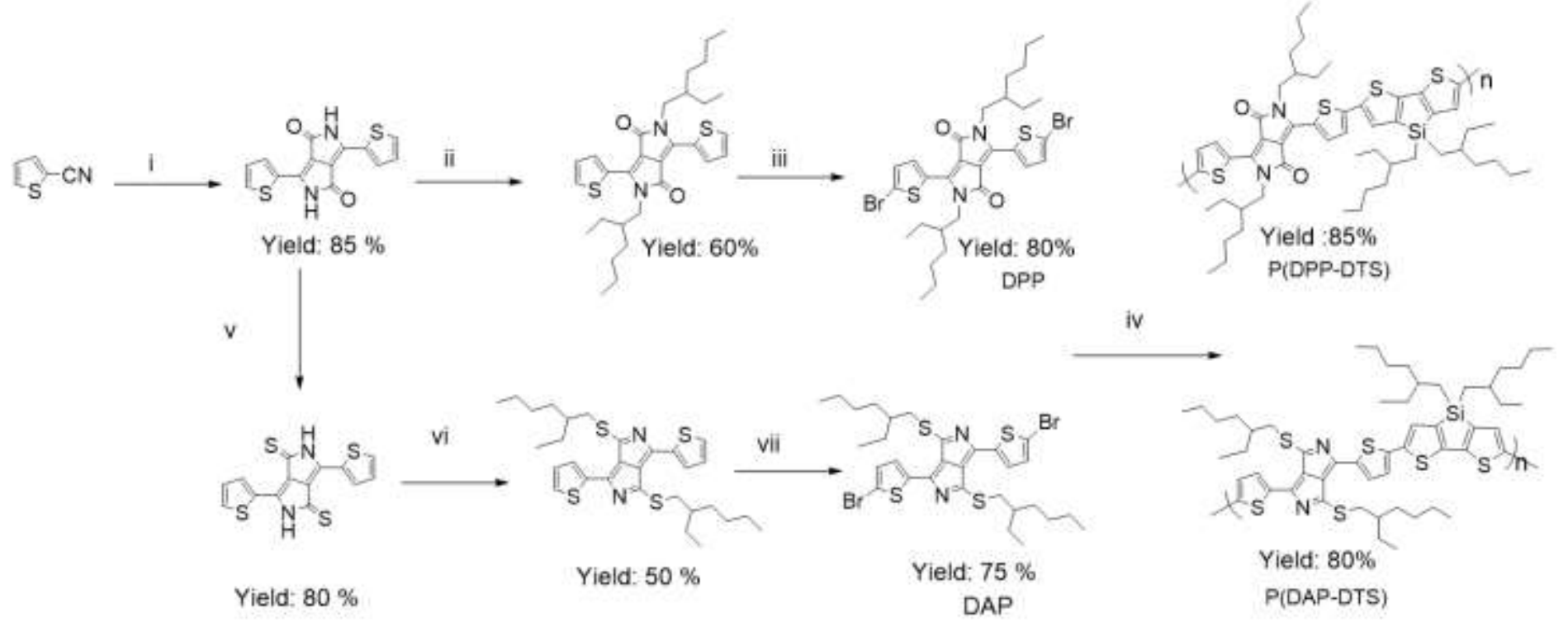

Scheme 1: Synthetic routes to monomers and copolymers. Conditions and reagents: i) sodium, iron chloride, tamyl alcohol, di-isopropylsuccinate; ii) $\mathrm{K}_{2} \mathrm{CO}_{3}, \mathrm{~N}, \mathrm{~N}$-dimethylformamide (DMF), EthylHexylBromide; iii) $\mathrm{N}$ bromosuccinimide (NBS), $\mathrm{CHCl}_{3}$; iv) $\left.\mathrm{Pd}\left(\mathrm{dba}_{3}\right)_{2}, \mathrm{P}(\mathrm{o}-\mathrm{tol})_{3}, \mathrm{CB}, \mathrm{DTS}(\mathrm{Sn}) ; \mathrm{v}\right)$ Lawesson's reagent, chlorobenzene (CB); vi) $\mathrm{K}_{2} \mathrm{CO}_{3}$, Acetone, EthylHexylBromide; vii) $\mathrm{NBS}, \mathrm{CHCl}_{3}$.

Therefore, we decided to follow the route 2 in which the thiolactam is introduced from the beginning before the alkylation of the DPP monomer (step $\mathrm{v}$ in scheme 1). Then, the thioalkylation and bromation steps were successively performed (steps vi and vii) to obtain the DAP monomer. The choice of branched alkyl chains was made to improve the solubility of the monomers and consequently that of the copolymers. The DAP monomer was purified twice through silica column flash chromatography. Finally, this monomer was copolymerized with di-stanilated dithienosilole via Stille polycondensation catalyzed by a palladium complex in chlorobenzene (CB) at $140^{\circ} \mathrm{C}$ for $3 \mathrm{~h}$ (step iv in scheme 1). The copolymer was purified through Soxhlet extraction and the chloroform fraction was collected. The chemical structures of the products, monomers and polymers were confirmed by ${ }^{1} \mathrm{H}$ NMR (see supporting information, figure SI1 to SI4). Finally, the P(DAP-DTS) was analyzed by size exclusion chromatography, the dispersity was 4.3 and the average molar mass in number was $\mathrm{Mn}=$ 10000 g.mol ${ }^{-1}$ (using conventional calibration with polystyrene samples).

\subsection{Halochromic properties}




\subsubsection{Brønsted acids}

The halochromic behavior of DAP and P(DAP-DTS) was first demonstrated by spectrophotometry by addition of hydrochloric acid $(\mathrm{HCl})$ in chloroform solutions. Figure 1a shows absorption spectra in the UV-visible region for the monomers and the NIR domain for the polymers. The protonation of the DAP monomer induces a bathochromic shift of $0.25 \mathrm{eV}(75 \mathrm{~nm})$ of the lowest absorption band from $565 \mathrm{~nm}$ to $640 \mathrm{~nm}$ (Table 1). The polymers present broader bands compared to the monomers but a strong redshift is observed in this case of 0.31 $\mathrm{eV}(225 \mathrm{~nm})$ upon protonation, i.e. from the first $(842 \mathrm{~nm})$ to the second NIR window $(1067 \mathrm{~nm})$.

Table 1: Optical and Electrochemical characteristics of materials developed in this study.

\begin{tabular}{|c|c|c|c|c|c|c|c|c|}
\hline Material & $\begin{array}{l}\lambda_{\max }{ }^{\mathrm{a}} \\
(\mathrm{nm})\end{array}$ & $\begin{array}{c}\mathrm{E}_{\left(\lambda_{\max }\right)} \\
(\mathrm{eV})\end{array}$ & $\begin{array}{c}\Delta E_{01}^{\infty \mathrm{c}} \\
(\mathrm{eV})\end{array}$ & $\begin{array}{l}\lambda_{\text {onset }^{a}} \\
(\mathrm{~nm})\end{array}$ & $\begin{array}{l}\mathrm{E}_{\mathrm{g}}^{\mathrm{a}} \\
(\mathrm{eV})\end{array}$ & $\begin{array}{c}\mathrm{E}_{\text {Номо }}{ }^{\mathrm{b}} \\
(\mathrm{eV})\end{array}$ & $\begin{array}{c}\mathrm{E}_{\text {LUMO }}{ }^{\mathrm{b}} \\
(\mathrm{eV})\end{array}$ & $\begin{array}{l}\mathrm{E}_{\mathrm{g}}^{\mathrm{b}} \\
(\mathrm{eV})\end{array}$ \\
\hline$\overline{D A P}$ & 565 & 2.19 & - & 640 & 1.94 & -6.1 & -3.7 & 2.4 \\
\hline$D A P-H^{+}$ & 640 & 1.94 & - & 675 & 1.84 & -5.8 & -3.9 & 1.9 \\
\hline $\mathrm{DAP}-\mathrm{BF}_{3}$ & 675 & 1.84 & - & 710 & 1.75 & -5.7 & -3.8 & 1.9 \\
\hline$P(D A P-D T S)$ & 842 & 1.47 & 1.67 & 1050 & 1.18 & -5.4 & -4.1 & 1.3 \\
\hline$P(D A P-D T S)-H^{+}$ & 1067 & 1.16 & 1.46 & 1400 & 0.89 & -5.3 & -4.2 & 1.1 \\
\hline$P(D A P-D T S)-B F_{3}$ & 1086 & 1.14 & $1.67 / 1.45^{d}$ & 1420 & 0.87 & -5.3 & -4.4 & 0.9 \\
\hline
\end{tabular}

${ }^{a}$ Measured by spectrophotometry in chloroform; ${ }^{\mathrm{b}}$ measured by cyclic voltammetry $\mathrm{E}_{\mathrm{HOMO}}=-\left(\mathrm{E}_{\mathrm{ox}}+4.7\right)$ and $\mathrm{E}_{\mathrm{LUMO}}=$

- $\left(\mathrm{E}_{\mathrm{red}}+4.7\right) ;{ }^{\mathrm{c}}$ calculated at the IEFPCM:M06-2X/6-311G(d) level; ${ }^{d}$ calculated for P(DAP-DTS $)-B F_{3} / P(D A P-$ $D T S)-\left(B F_{3}\right)_{2}$. 

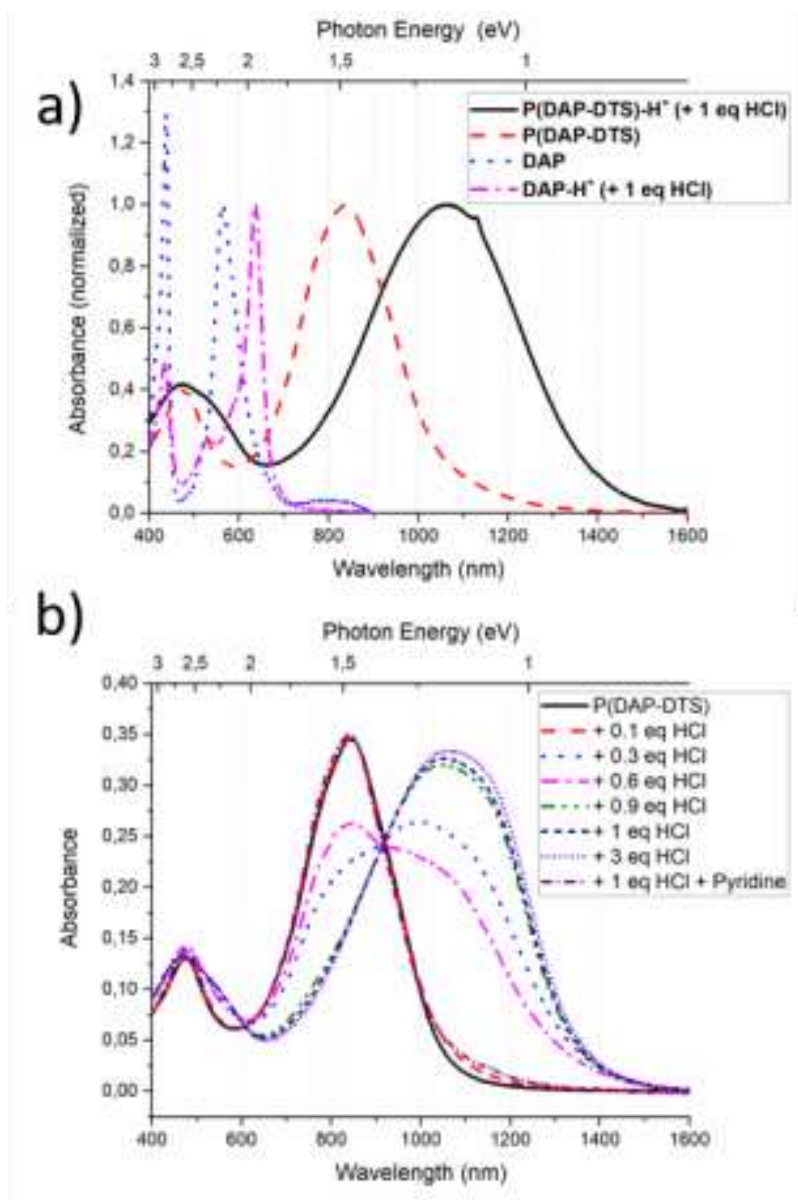

Figure 1: UV-visible-NIR absorption spectra in chloroform solution of a) DAP, protonated DAP (DAP-H ${ }^{+}$, $\mathrm{P}(\mathrm{DAP}-\mathrm{DTS})$ and protonated P(DAP-DTS) (P(DAP-DTS)-H $\left.{ }^{+}\right)$b) P(DAP-DTS) with increasing amount of HCl.

DFT calculations were performed to rationalize this behavior. Figure 2 illustrates the impact of protonation on the frontier energy levels and molecular orbital (MO) shapes of the DAP-DTS repeat unit, as calculated at the M06-2X/6-311G(d) level in chloroform. B3LYP/6-311G(d) results are provided in SI. In the neutral repeat unit, the HOMO is spread over both the DAP and DTS moieties, while the LUMO is essentially localized on the DAP acceptor. Protonation of the DAP unit induces a displacement of the HOMO density towards the DTS moiety, together with a large downshift of the frontier orbital energies. The shift of the HOMO energy $(-0.67$ $\mathrm{eV})$ is weaker than that of the LUMO $(-1.11 \mathrm{eV})$, which gives rise to a lowering of the electronic gap of 0.44 $\mathrm{eV}$, consistent with the decrease of the optical transition energy observed in UV-vis. measurements. The bond length alternation (BLA) along the conjugated backbone (see SI for details), which decreases from $0.045 \AA$ to $0.031 \AA$, also reveals an enhancement of the $\pi$-electron conjugation upon protonation. 


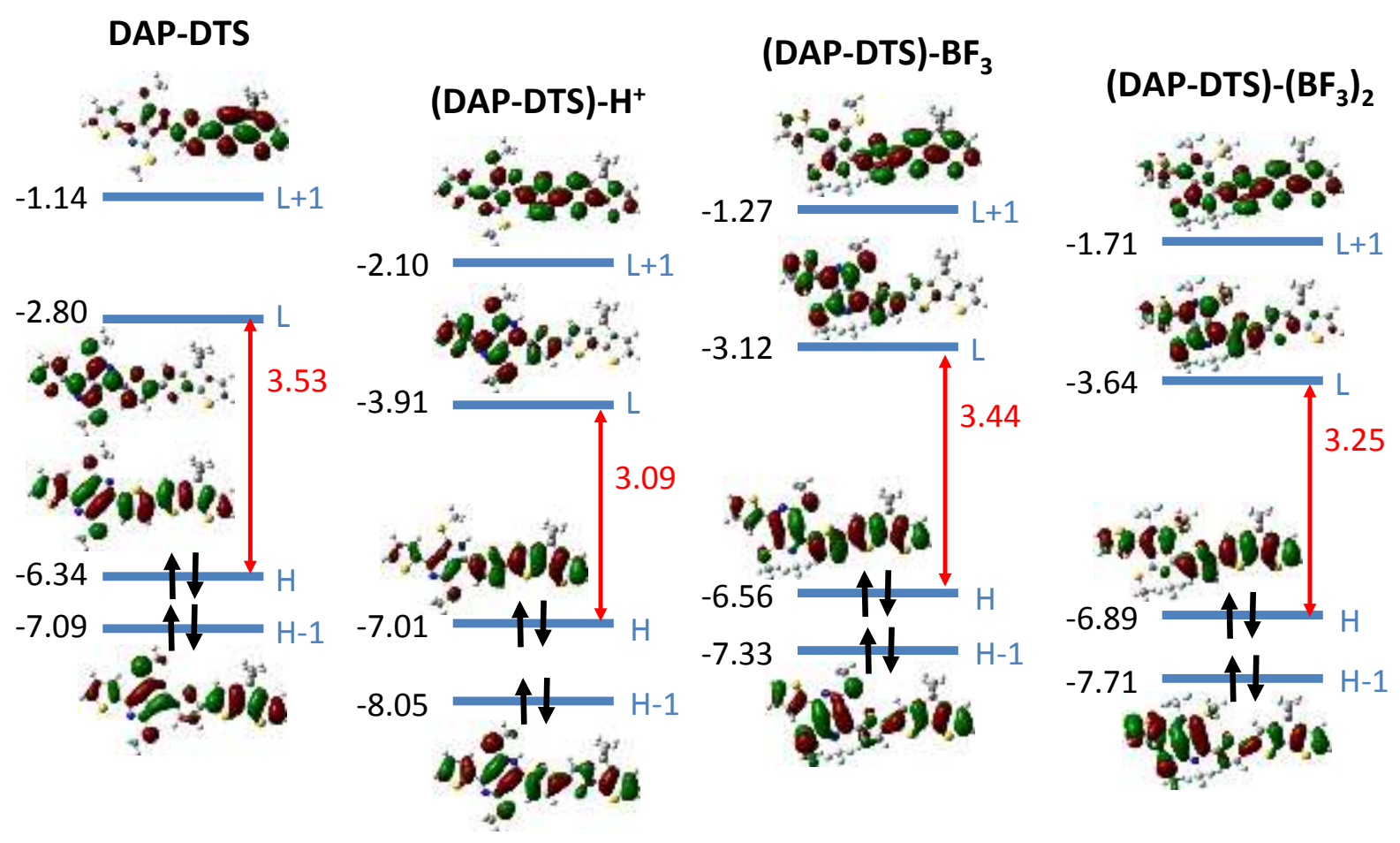

Figure 2: Frontier energy levels (with energy values in $\mathrm{eV}$ ) and molecular orbital shapes of DAP-DTS, (DAPDTS $)-\mathrm{H}^{+},(\mathrm{DAP}-\mathrm{DTS})-\mathrm{BF}_{3}$ and (DAP-DTS)-(BF $)_{2}$ monomers, calculated at the IEFPCM:M06-2X/6-311G(d) level in chloroform.

To gain further insight on the evolution of absorption properties with the number of repeating units, vertical transition energies towards the lowest excited state $\left(\Delta E_{01}\right)$ were calculated for increasingly large neutral and protonated DAP-DTS oligomers. Numerical values are reported in Tables SI1-2, while their evolution with chain length is shown in Figure 3. As a result of the decrease of the HOMO-LUMO gap with conjugation length, increasing the number of repeating units induces a significant lowering of $\Delta E_{01}$ for both neutral and protonated systems. The transition energies in the polymer limit $\left(\Delta E_{01}^{\infty}\right)$, obtained by fitting the computed transition energies with Equation 1, amount to $1.67 \mathrm{eV}(742 \mathrm{~nm})$ and $1.46 \mathrm{eV}(849 \mathrm{~nm})$ for the neutral and protonated polymers, respectively. The calculated redshift induced by protonation $(0.21 \mathrm{eV})$ qualitatively reproduces the experimental displacement $(0.31 \mathrm{eV})$ of the main absorption band. As indicated by the optimal values of the fitting parameters $E_{1}$ and $D_{k}$ (see SI), the large decrease of $\Delta E_{01}^{\infty}$ upon protonation is essentially driven by the decrease of $E_{1}$, related to the transition energy of the repeating unit. 


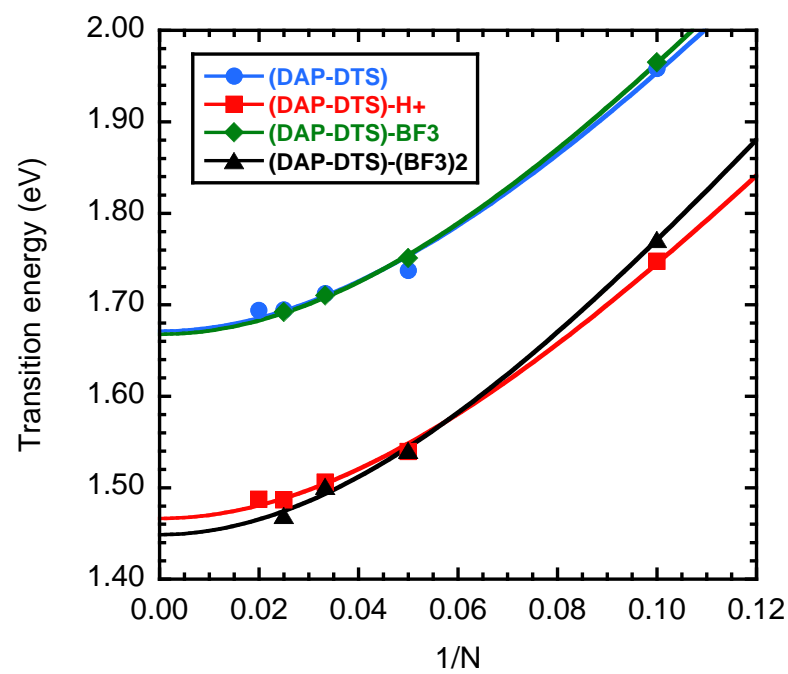

Figure 3: Evolution with chain length of the vertical transition energies $\left(\Delta E_{01}, \mathrm{eV}\right)$ of neutral and protonated DAP-DTS oligomers, as calculated at the IEF-PCM/M06-2X/6-311G(d) in chloroform. Lines are fits calculated according to equation 1. Optimized values of the Kuhn fit parameters are given in SI. $\mathrm{N}$ is the number of conjugated double bonds in the polymer skeleton and a repeat unit contains ten double bonds.

Figure $1 \mathrm{~b}$ presents the experimental visible-near IR spectra of the polymer solution protonated in presence of different equivalents of $\mathrm{HCl}$. The amount of $\mathrm{HCl}$ was calculated from the DAP-DTS repeat unit so that 1 equivalent of $\mathrm{HCl}$ means that one acid molecule was added for one repeat unit. Incremental additions of $\mathrm{HCl}$ gave rise to a lowering of the intensity of the peak pertaining to the neutral chromophore, with absorption maximum $\left(\lambda_{\max }\right)$ at $842 \mathrm{~nm}$ and onset $\left(\lambda_{\text {onset }}\right)$ at $1050 \mathrm{~nm}$, and to the growth of a second broad band pertaining to the protonated form, with $\lambda_{\max }$ above $1000 \mathrm{~nm}$ and $\lambda_{\text {onset }}$ at $1400 \mathrm{~nm}$. To our knowledge, this halochromic behavior is associated to the highest reported wavelength shift in the infrared. ${ }^{15,23,40}$ After addition of 1 equivalent of $\mathrm{HCl}$ the absorption peak was completely shifted and an isosbestic point was observed at $919 \mathrm{~nm}$, indicating that only the neutral and protonated absorption species exist in solution. This was confirmed by the evaluation of the absorption electronic spectra of the neutral and protonated forms (figure in supporting information), in which extinction coefficient $(\varepsilon)$ were measured around $5600 \mathrm{~L} \cdot \mathrm{mol}^{-1} . \mathrm{cm}^{-1}$ for the absorbance maxima and the isobestic point was observed at $919 \mathrm{~nm}\left(\varepsilon=4030 \mathrm{~L} \cdot \mathrm{mol}^{-1} \cdot \mathrm{cm}^{-1}\right)$. Moreover, adding $\mathrm{HCl}$ in excess (3 eq.) did not change further absorption spectra, which reached a saturation limit for 1 equivalent of $\mathrm{HCl}$. Since each DAP unit bears two nitrogen sites that are likely to be protonated, the exact nature of the protonated structure was questioned. The fact that one and three equivalents of $\mathrm{HCl}$ led to the same absorption 
spectra suggested that structures with two protons on the same monomer are not formed. This hypothesis was confirmed by calculating at the M06-2X/6-311G(d) level the energy differences of di-protonated oligomers with protons located either on different or on the same DAP unit. The results provided in SI show that the latter structures are higher in energy by about $28 \mathrm{kcal} / \mathrm{mol}$, which impedes the protonation reaction of the second nitrogen atom.

Finally, the absorption spectrum of the initial neutral polymer was recovered after addition of pyridine to the protonated polymer (Figure 1b), confirming its reversible halochromic behavior. Halochromic properties of the P(DAP-DTS) polymer were also observed using the trifluoroacetic acid (TFA). However, the addition of one equivalent of this organic acid per DAP repeat unit did not lead to the complete shift of the spectrophotometric signal, which required a 20-fold excess of TFA. This behavior was ascribed to the weaker acidity of TFA $\left(\mathrm{pKa}_{/ \mathrm{w}}=0.2\right)$ compared to $\mathrm{HCl}(\mathrm{pKa} / \mathrm{w}=-6.0) .{ }^{41-42}$

\subsubsection{Lewis acid}

DAP basic nitrogen atoms in the aromatic ring are also able to bind Lewis acids through dative bonds. Compared to protonation, this strategy allows modulation of optical properties via the Lewis acid strength, and, since these acids are covalently bonded, avoiding the presence of free mobile counter ions in the matrix. To the neutral P(DAP-DTS) was added an incremental amount of boron trifluoride, $\mathrm{BF}_{3}$, a strong Lewis acid. Figure 4a shows the evolution of the absorption spectra of the modified copolymer. Once more, the signal at $\lambda_{\max }=$ $842 \mathrm{~nm}$ (Table 1) progressively vanished with the addition of $\mathrm{BF}_{3}$ and a second signal appeared with $\lambda_{\max }$ at $1100 \mathrm{~nm}$ and $\lambda_{\text {onset }}$ at $1420 \mathrm{~nm}$. The same behavior was observed on the DAP monomer, for which a redshift of $110 \mathrm{~nm}$ was observed upon $\mathrm{BF}_{3}$ addition (see Figure SI5). Contrary to what observed upon $\mathrm{HCl}$ addition, a complete shift of the first absorption band of the P(DAP-DTS) copolymer was not observed until two equivalents of boron trifluoride were introduced in the solution, which suggests that $\mathrm{BF}_{3}$ can bind the two nitrogen sites of a same DAP unit. This assumption was confirmed by DFT calculations (table SI5), which evidenced that (DAP-DTS) $-\mathrm{BF}_{3}$ dimers with two $\mathrm{BF}_{3}$ substituents on the same DAP unit are only $\sim 6 \mathrm{kcal} / \mathrm{mol}$ higher in energy than dimers with $\mathrm{BF}_{3}$ distributed on different DAP moieties, which is a much smaller energy difference than that computed in the case of di-protonated species. 
Moreover, as shown on Figure 2, grafting one $\mathrm{BF}_{3}$ group to the DAP-DTS monomer slightly lowers the HOMO-LUMO gap $(-0.09 \mathrm{eV})$, while two $\mathrm{BF}_{3}$ groups give rise to a much larger gap reduction of $0.29 \mathrm{eV}$. Again, this behavior can be correlated to the BLA along the $\pi$-conjugated skeleton, which decreases from 0.045 $\AA$ in the pristine DAP-DTS monomer to $0.043 \AA$ and $0.030 \AA$ upon addition of one and two $\mathrm{BF}_{3}$, respectively. Vertical transition energies extrapolated for P(DAP-DTS) $-\mathrm{BF}_{3}$ polymers (Figure 3) amount to $1.65 \mathrm{eV}$, which is really close to the one of the neutral polymer, while $\Delta E_{01}^{\infty}=1.45 \mathrm{eV}$ for P(DAP-DTS)-(BF $)_{2}$. Experimentally the complexation of the polymers with one $\mathrm{BF}_{3}$ per $\mathrm{DAP}$ may not be apparent from the $\mathrm{UV}$-visible spectrum in figure $4 \mathrm{a}$ because the absorbance of the $\mathrm{P}(\mathrm{DAP}-\mathrm{DTS})-\mathrm{BF}_{3}$ is therefore supposed to be really close to the one of the neutral polymer. The transition energy extrapolated for P(DAP-DTS)- $\left(\mathrm{BF}_{3}\right)_{2}$ is slightly smaller than that computed for the protonated polymers in agreement with experiments, and further indicates that the absorption band measured at $1100 \mathrm{~nm}$ originates from the formation of copolymers with two $\mathrm{BF}_{3}$ per DAP-DTS unit.
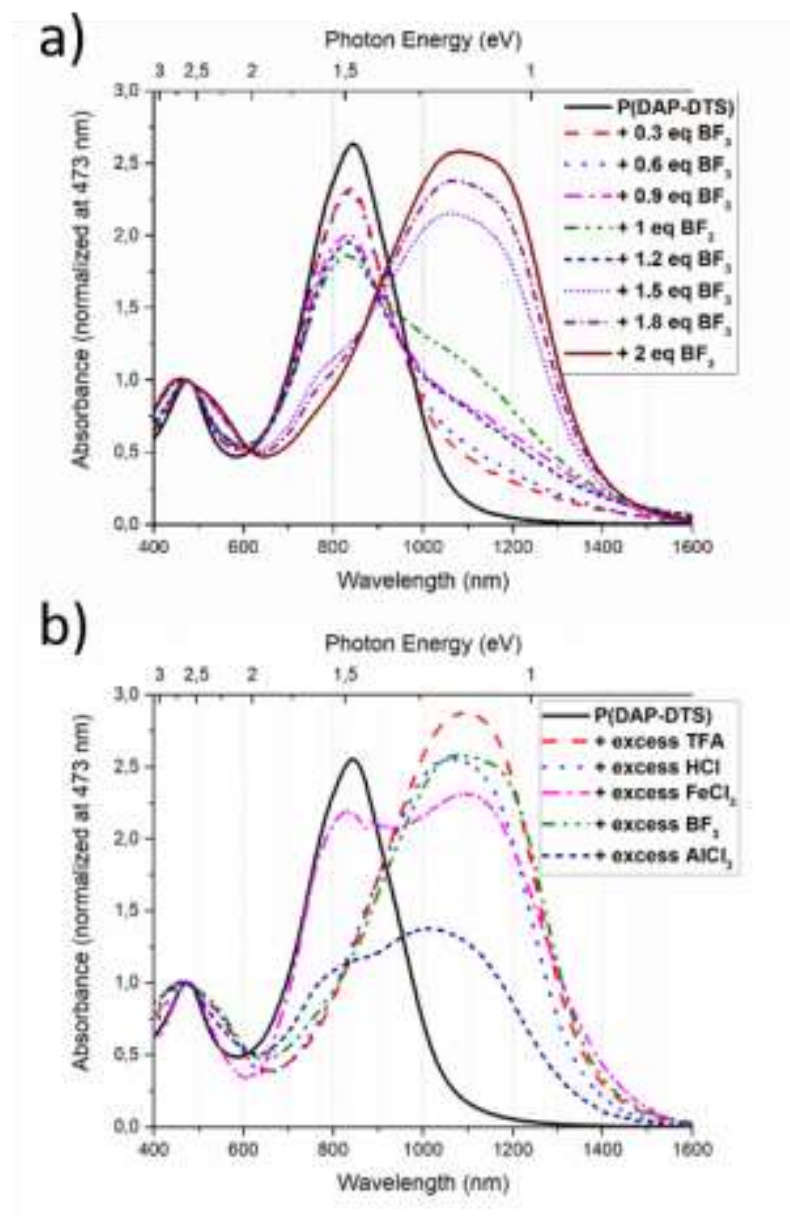

Figure 4: Normalized UV-visible-NIR absorption spectra of a) P(DAP-DTS) with increasing amount of $\mathrm{BF}_{3}$ in chloroform solution; b) P(DAP-DTS) adding excess amount of $\mathrm{HCl}$ (1 eq), TFA (20 eq), $\mathrm{BF}_{3}$ (2 eq) $\mathrm{AlCl}_{3}(10$ eq) and $\mathrm{FeCl}_{3}(10 \mathrm{eq})$ in chloroform solution. 
Finally, to explore the general trend of the band gap modification, different Lewis acids, namely $\mathrm{FeCl}_{3}, \mathrm{AlCl}_{3}$ and $\mathrm{BF}_{3}$ were added to the copolymer in chloroform solution, and the UV-visible-NIR spectra of the resulting mixtures were recorded. As can be seen in Figure 4b, a series of red-shifted complexes that cover most of the visible-NIR region from 700 to $1400 \mathrm{~nm}$ were obtained. The strength of the Lewis acid varies, from the strongest to the weakest, as $\mathrm{BF}_{3}>\mathrm{AlCl}_{3}>\mathrm{FeCl}_{3}$. ${ }^{43}$ Unlike the $\mathrm{BF}_{3}$ adduct which is readily formed after the addition of two acid equivalents, both $\mathrm{AlCl}_{3}$ and $\mathrm{FeCl}_{3}$ did not lead to a complete shift of the spectroscopic signal even after a ten-fold excess of the acids. Moreover, the polymer- $\mathrm{FeCl}_{3}$ or $\mathrm{AlCl}_{3}$ complexes were less stable than their $\mathrm{BF}_{3}$ counterpart in chloroform, and tended to precipitate.

\subsection{Electrochemical characterizations}

The redox potentials of the neutral DAP and P(DAP-DTS), as well as those obtained after protonation with $\mathrm{HCl}$ and their $\mathrm{BF}_{3}$ adduct, were determined by cyclic voltammetry, analyzing films, drop-casted onto a platinium electrode, in dry acetonitrile using $\mathrm{TBAPF}_{6}$ as supporting electrolyte (voltammograms in SI). All compounds were electrochemically active, exhibiting quite reversible redox waves. When submitted to potential scanning from 0 to $-1.5 \mathrm{eV}$ (versus SCE), a clear and reversible reduction peak was observed pertaining to the reduction of electron-deficient DAP cores. When the potential was scanned from 0 to $+1.4 \mathrm{eV}$ (versus $\mathrm{SCE}$ ) an irreversible oxidation of the compounds was observed. The HOMO and LUMO levels (in eV, ref. vacuum) of monomers and copolymers were deduced from the oxidation and reduction potentials and reported in Table 1 . Due to the extended conjugation and the use of strong donor and acceptor monomers, copolymers showed small energy gaps in the range of $0.9-1.3 \mathrm{eV}$ (Table 1). In agreement with DFT calculations, acid treatments of the DAP-based copolymer led to the decrease of both LUMO and HOMO levels, but affected more the LUMO level and consequently decreased the band gap.

\section{Conclusion}

In summary, we applied a simple method to tune the optoelectronic properties of a new diazapentalenedithienosilole alternated copolymer, with the objective to shift its maximum absorbance from the first to the 
second near infrared window (both in solution and in thin film, see supporting information). We showed that the addition of Bronsted or Lewis acids induces a significant redshift in the absorbance of the polymer. A combination of UV/vis/NIR spectroscopy, cyclic voltammetry and DFT calculations proved that this optical shift is correlated with a decrease of the copolymers band-gap, associated to the decrease in the LUMO energy and enhancement of the $\pi$-electron delocalization along the conjugated backbone, as revealed by the lowering of bond length alternation. Since they can undergo analyte-induced shifts in their absorption and probably emission bands in the near infrared, these materials should prove useful as biological/chemical sensors.

\section{Acknowledgements}

The Agence Nationale de la Recherche (TAPIR project no. ANR-15-CE24-0024-02) and the Région Nouvelle Aquitaine (TAMANOIR project no. 2016-1R10105-0007207) are gratefully acknowledged for their financial support. Computer time was provided by the Pôle Modélisation HPC facilities of the Institut des Sciences Moléculaires, co-funded by the Nouvelle Aquitaine region, as well as by the MCIA (Mésocentre de Calcul Intensif Aquitain) resources of the Université de Bordeaux and of the Université de Pau et des Pays de l'Adour.

Supporting Information. Experimental details and additional characterization data. This material is available free of charge via the Internet at http://pubs.acs.org.

\section{References}

1. Boudreault, P.-L. T.; Najari, A.; Leclerc, M., Processable Low-Bandgap Polymers for Photovoltaic Applications. Chemistry of Materials 2011, 23 (3), 456-469.

2. Liu, C.; Wang, K.; Gong, X.; Heeger, A. J., Low bandgap semiconducting polymers for polymeric photovoltaics. Chemical Society Reviews 2016, 45 (17), 4825-4846.

3. Dou, L.; Liu, Y.; Hong, Z.; Li, G.; Yang, Y., Low-Bandgap Near-IR Conjugated Polymers/Molecules for Organic Electronics. Chemical Reviews 2015, 115 (23), 12633-12665.

4. Faïd, K.; Leclerc, M., Functionalized regioregular polythiophenes: Towards the development of biochromic sensors. Chemical Communications 1996, (24), 2761-2762.

5. Rughooputh, S. D. D. V.; Hotta, S.; Heeger, A. J.; Wudl, F., Chromism of soluble polythienylenes. Journal of Polymer Science Part B: Polymer Physics 1987, 25 (5), 1071-1078.

6. Lévesque, I.; Leclerc, M., Ionochromic and thermochromic phenomena in a regioregular polythiophene derivative bearing oligo(oxyethylene) side chains. Chemistry of Materials 1996, 8 (12), 2843-2849. 
7. Lee, Y.-H.; Yen, W.-C.; Su, W.-F.; Dai, C.-A., Self-assembly and phase transformations of [small pi]-conjugated block copolymers that bend and twist: from rigid-rod nanowires to highly curvaceous gyroids. Soft Matter 2011, 7 (21), 10429-10442.

8. Lee, Y. H.; Yen, W. C.; Su, W. F.; Dai, C. A., Self-assembly and phase transformations of $\pi$-conjugated block copolymers that bend and twist: From rigid-rod nanowires to highly curvaceous gyroids. Soft Matter 2011, 7 (21), 10429-10442.

9. Oh, J. Y.; Shin, M.; Lee, T. I.; Jang, W. S.; Min, Y.; Myoung, J. M.; Baik, H. K.; Jeong, U., Self-seeded growth of poly(3-hexylthiophene) (P3HT) nanofibrils by a cycle of cooling and heating in solutions. Macromolecules 2012, 45 (18), 7504-7513.

10. De Silva, A. P.; Gunaratne, H. Q. N.; McCoy, C. P., Direct visual indication of pH windows: 'off-on-off' fluorescent PET (photoinduced electron transfer) sensors/switches. Chemical Communications 1996, (21), 2399-2400.

11. Monkman, A. P.; Pålsson, L. O.; Higgins, R. W. T.; Wang, C.; Bryce, M. R.; Batsanov, A. S.; Howard, J. A. K., Protonation and subsequent intramolecular hydrogen bonding as a method to control chain structure and tune luminescence in heteroatomic conjugated polymers. Journal of the American Chemical Society 2002, 124 (21), 60496055.

12. Randell, N. M.; Fransishyn, K. M.; Kelly, T. L., Lewis Acid-Base Chemistry of 7-Azaisoindigo-Based Organic Semiconductors. ACS Applied Materials and Interfaces 2017, 9 (29), 24788-24796.

13. Hayashi, S.; Asano, A.; Koizumi, T., Modification of pyridine-based conjugated polymer films via Lewis acid: halochromism, characterization and macroscopic gradation patterning. Polymer Chemistry 2011, 2 (12), 2764-2766.

14. Qian, G.; Qi, J.; Davey, J. A.; Wright, J. S.; Wang, Z. Y., Family of Diazapentalene Chromophores and NarrowBand-Gap Polymers: Synthesis, Halochromism, Halofluorism, and Visible-Near Infrared Photodetectivity. Chemistry of Materials 2012, 24 (12), 2364-2372.

15. Qian, G.; Wang, Z. Y., Near-infrared thermochromic diazapentalene dyes. Advanced Materials 2012, 24 (12), $1582-1588$.

16. Welch, G. C.; Coffin, R.; Peet, J.; Bazan, G. C., Band gap control in conjugated oligomers via Lewis acids. Journal of the American Chemical Society 2009, 131 (31), 10802-10803.

17. Zalar, P.; Henson, Z. B.; Welch, G. C.; Bazan, G. C.; Nguyen, T. Q., Color tuning in polymer light-emitting diodes with lewis acids. Angewandte Chemie - International Edition 2012, 51 (30), 7495-7498.

18. Lin, J.; Liu, B.; Yu, M.; Xie, L.; Zhu, W.; Ling, H.; Zhang, X.; Ding, X.; Wang, X.; Stavrinou, P. N.; Wang, J.; Bradley, D. D. C.; Huang, W., Heteroatomic Conjugated Polymers and the Spectral Tuning of Electroluminescence via a Supramolecular Coordination Strategy. Macromolecular Rapid Communications 2016, 37 (22), 1807-1813.

19. Myochin, T.; Kiyose, K.; Hanaoka, K.; Kojima, H.; Terai, T.; Nagano, T., Rational design of ratiometric nearinfrared fluorescent $\mathrm{pH}$ probes with various pKa values, based on aminocyanine. Journal of the American Chemical Society 2011, 133 (10), 3401-3409.

20. Ameri, T.; Khoram, P.; Min, J.; Brabec, C. J., Organic ternary solar cells: A review. Advanced Materials 2013, 25 (31), 4245-4266.

21. Hendriks, K. H.; Li, W.; Wienk, M. M.; Janssen, R. A. J., Small-bandgap semiconducting polymers with high nearinfrared photoresponse. Journal of the American Chemical Society 2014, 136 (34), 12130-12136.

22. Croissant, J. G.; Zink, J. I.; Raehm, L.; Durand, J.-O., Two-Photon-Excited Silica and Organosilica Nanoparticles for Spatiotemporal Cancer Treatment. Advanced Healthcare Materials, 2018, 1701248-1701271.

23. Qi, J.; Qiao, W.; Wang, Z. Y., Advances in Organic Near-Infrared Materials and Emerging Applications. Chemical Record 2016, 3, 1531-1548.

24. He, Y.; Cao, Y.; Wang, Y., Progress on Photothermal Conversion in the Second NIR Window Based on Conjugated Polymers. Asian Journal of Organic Chemistry 2018, 7 (11), 2201-2212.

25. Cheng, P.; Zhan, X., Stability of organic solar cells: challenges and strategies. Chemical Society Reviews 2016, 45 (9), 2544-2582.

26. Brédas, J. L.; Silbey, R.; Boudreaux, D. S.; Chance, R. R., Chain-length dependence of electronic and electrochemical properties of conjugated systems: Polyacetylene, polyphenylene, polythiophene, and polypyrrole. Journal of the American Chemical Society 1983, 105 (22), 6555-6559.

27. Gierschner, J.; Cornil, J.; Egelhaaf, H. J., Optical bandgaps of $\pi$-conjugated organic materials at the polymer limit: Experiment and theory. Advanced Materials 2007, 19 (2), 173-191.

28. Wykes, M.; Milián-Medina, B.; Gierschner, J., Computational engineering of low bandgap copolymers. Frontiers in Chemistry 2013, 1, 35-47.

29. Oliveira, E. F.; Roldao, J. C.; Milián-Medina, B.; Lavarda, F. C.; Gierschner, J., Calculation of low bandgap homopolymers: Comparison of TD-DFT methods with experimental oligomer series. Chemical Physics Letters 2016, 645, 169-173.

30. Torras, J.; Casanovas, J.; Alemán, C., Reviewing extrapolation procedures of the electronic properties on the $\pi$ conjugated polymer limit. Journal of Physical Chemistry A 2012, 116 (28), 7571-7583. 
31. Karsten, B. P.; Viani, L.; Gierschner, J.; Cornil, J.; Janssen, R. A. J., An oligomer study on small band gap polymers. Journal of Physical Chemistry A 2008, 112 (43), 10764-10773.

32. Fradon, A.; Cloutet, E.; Hadziioannou, G.; Brochon, C.; Castet, F., Optical properties of donor-acceptor conjugated copolymers: A computational study. Chemical Physics Letters 2017, 678, 9-16.

33. Zhao, Y.; Truhlar, D. G., The M06 suite of density functionals for main group thermochemistry, thermochemical kinetics, noncovalent interactions, excited states, and transition elements: Two new functionals and systematic testing of four M06-class functionals and 12 other functionals. Theoretical Chemistry Accounts 2008, 120 (1-3), 215-241.

34. Sancho-García, J. C.; Pérez-Jiménez, A. J., Improved accuracy with medium cost computational methods for the evaluation of bond length alternation of increasingly long oligoacetylenes. Physical Chemistry Chemical Physics 2007, 9 (44), 5874-5879.

35. Torrent-Sucarrat, M.; Navarro, S.; Cossío, F. P.; Anglada, J. M.; Luis, J. M., Relevance of the DFT method to study expanded porphyrins with different topologies. Journal of Computational Chemistry 2017, 38 (32), 2819-2828.

36. Méndez-Hernández, D. D.; Tarakeshwar, P.; Gust, D.; Moore, T. A.; Moore, A. L.; Mujica, V., Simple and accurate correlation of experimental redox potentials and DFT-calculated HOMO/LUMO energies of polycyclic aromatic hydrocarbons. Journal of Molecular Modeling 2013, 19 (7), 2845-2848.

37. Tomasi, J.; Mennucci, B.; Cammi, R., Quantum mechanical continuum solvation models. Chemical Reviews 2005, 105 (8), 2999-3093.

38. Kuhn, W., Über das Absorptionsspektrum der Polyene. Helvetica Chimica Acta 1948, 31 (6), 1780-1799.

39. M. J. Frisch, G. W. T., H. B. Schlegel, G. E. Scuseria, M. A. Robb, J. R. Cheeseman, G. Scalmani, V. Barone, B. Mennucci, G. A. Petersson, H. Nakatsuji, M. Caricato, X. Li, H. P. Hratchian, A. F. Izmaylov, J. Bloino, G. Zheng, J. L. Sonnenberg, M. Hada, M. Ehara, K. Toyota, R. Fukuda, J. Hasegawa, M. Ishida, T. Nakajima, Y. Honda, O. Kitao, H. Nakai, T. Vreven, J. A. Montgomery, Jr., J. E. Peralta, F. Ogliaro, M. Bearpark, J. J. Heyd, E. Brothers, K. N. Kudin, V. N. Staroverov, R. Kobayashi, J. Normand, K. Raghavachari, A. Rendell, J. C. Burant, S. S. Iyengar, J. Tomasi, M. Cossi, N. Rega, J. M. Millam, M. Klene, J. E. Knox, J. B. Cross, V. Bakken, C. Adamo, J. Jaramillo, R. Gomperts, R. E. Strat- mann, O. Yazyev, A. J. Austin, R. Cammi, C. Pomelli, J. W. Ochterski, R. L. Martin, K. Morokuma, V. G. Zakrzewski, G. A. Voth, P. Salvador, J. J. Dannenberg, S. Dapprich, A. D. Daniels, Farkas, J. B. Foresman, J. V. Ortiz, J. Cioslowski and D. J. Fox, Gaussian 09 revision D01, Gaussian Inc. Wallingford CT 2009.

40. Welterlich, I.; Tieke, B., Dithioketopyrrolopyrrole (DTPP)-based conjugated polymers prepared upon thionation with Lawesson's reagent. Polymer Chemistry 2013, 4 (13), 3755-3764.

41. Lussier, L. S.; Sandorfy, C.; Le Thanh, H.; Vocelle, D., Effect of acids on the infrared spectra of the Schiff base of trans-retinal. The Journal of Physical Chemistry 1987, 91 (9), 2282-2287.

42. Kütt, A.; Selberg, S.; Kaljurand, I.; Tshepelevitsh, S.; Heering, A.; Darnell, A.; Kaupmees, K.; Piirsalu, M.; Leito, I., pKa values in organic chemistry - Making maximum use of the available data. Tetrahedron Letters 2018, 59 (42), 37383748.

43. Brown, I. D.; Skowron, A., Electronegativity and Lewis acid strength. Journal of the American Chemical Society 1990, 112 (9), 3401-3403. 